\title{
Strategy-proof preference rules
}

\author{
Citation for published version (APA):
}

Storcken, A. J. A. (1995). Strategy-proof preference rules. METEOR, Maastricht University School of Business and Economics. METEOR Research Memorandum No. 017 https://doi.org/10.26481/umamet.1995017

Document status and date:

Published: 01/01/1995

DOI:

10.26481/umamet.1995017

Document Version:

Publisher's PDF, also known as Version of record

\section{Please check the document version of this publication:}

- A submitted manuscript is the version of the article upon submission and before peer-review. There can be important differences between the submitted version and the official published version of record.

People interested in the research are advised to contact the author for the final version of the publication, or visit the DOI to the publisher's website.

- The final author version and the galley proof are versions of the publication after peer review.

- The final published version features the final layout of the paper including the volume, issue and page numbers.

Link to publication

\footnotetext{
General rights rights.

- You may freely distribute the URL identifying the publication in the public portal. please follow below link for the End User Agreement:

www.umlib.nl/taverne-license

Take down policy

If you believe that this document breaches copyright please contact us at:

repository@maastrichtuniversity.nl

providing details and we will investigate your claim.
}

Copyright and moral rights for the publications made accessible in the public portal are retained by the authors and/or other copyright owners and it is a condition of accessing publications that users recognise and abide by the legal requirements associated with these

- Users may download and print one copy of any publication from the public portal for the purpose of private study or research.

- You may not further distribute the material or use it for any profit-making activity or commercial gain

If the publication is distributed under the terms of Article $25 \mathrm{fa}$ of the Dutch Copyright Act, indicated by the "Taverne" license above, 


\title{
STRATEGY-PROOF PREFERENCE RULES
}

\author{
by Ton Storcken ${ }^{1}$
}

\begin{abstract}
By virtue of the Kemeny distance strategy-proofness of preference rules is defined. It is shown that a preference rule, which assigns a complete relation to every profile of complete relations is non-imposed and strategy-proof if and only if it is pairwise voting in committees. So, non-imposedness and strategy-proofness together imply the independence of irrelevant alternatives condition. Furthermore, it is shown that in this setting pairwise voting in committees coincides with coordinatewise veto voting. Taking acyclic preference rules into consideration, which assign an acyclic complete relation to every profile of acyclic complete relations, it follows that under strategy-proofness and non-imposition the independence of irrelevant alternatives is equivalent to indifference monotonicity. Now it follows that an acyclic preference rule is non-imposed, strategy-proof and indifference monotonic if and only if it is coordinatewise veto voting with respect to a cycle free assignment of disagreements.
\end{abstract}

1 University of Limburg, Faculty of Economics, P.O. Box 616, 6200 MD Maastricht, The Netherlands. 


\section{§1. StRategy Proofness}

The vulnerability for strategic behavior of a collective decision rule is and was an important issue. This is for several reasons e.g. a right decision is more likely to evolve from the right individual opinions than from strategically pretended ones. Also, it may be regarded as ethically unfair that the benefit obtained by some due to their strategic behavior is on the expense of others who did not act strategically or who were less fortunate with their pretended behavior. Furthermore, a strategy-proof rule is simple because strategic behavior of others need not be taken into account and the best individual action is straightforward truth telling.

There are many earlier contributions on this subject (see for instance Gibbard [1973], Satterthwaite [1975], Gärdenfors [1976], Barberà [1977], Kelly [1977], Feldman [1979], Dutta [1982], Bandyopadhyay [1983] among many others; surveys on this subject are for instance Pattanaik [1978] and Sen [1986]). In all these approaches the collective decision rules under consideration are either social choice funcions yielding as outcomes single alternatives or social choice correspondences yielding as outcomes nonempty subsets of alternatives. In Bossert and Storcken [1992] strategyproofness is discussed with respect to an other type of collective decision rules, namely social welfare functions. These functions aggregate the individual points of view into a "social" preference ordering.

The importance of the impossibility of manipulation in this latter framework can be illustrated by the following. Suppose the group of agents does not have a specific choice situation in mind and therefore applies a certain social welfare function. By this a social ranking of the alternatives is achievable which can be used to determine the group choice at any choice situation. Suppose furthermore, that at the time the social ranking of all alternatives is determined it is unknown which paricular subset of the set of alternatives becomes feasible. Then not only the best alternative of the social ranking is important but the whole ranking. Consequently, the whole ranking is to be considered and strategic behavior becomes an interesting issue for such social welfare funcions. In Bossert and Storcken [1992] an explicit example for those situations is provided.

Strategy-proofness for collective decision rules means that an agent cannot benefit from insincere preference revelation. As the outcomes of a social welfare function are orderings, we have to make assumptions about how agents can order the 
outcomes of a social welfare function. Consequently, we have to define a way in which agents are able to compare the possible social rankings. Of course these comparisons depend on the individual orderings of the agents. Like in Bossert and Storcken [1992], this comparison is based on the Kemeny distance, see e.g. Kemeny and Snell [1962]. It is assumed that an individual prefers social ranking $R$ above social ranking $R^{\prime}$ if the distance between his (sincere) preference relation and $\mathrm{R}$ is smaller than the distance between his preference relation and R'.

In Bossert and Storcken [1992] it is assumed that the social ranking as well as the individual preferences are linear orderings, i.e. antisymmetric, complete and transitive relations. In this setting they found that only dictatorial welfare functions are strategy-proof, non-imposed and weakly extrema indepent if in addition there are four alternatives. Here we will study two other sets of orderings.

The first set of orderings under consideration is the set of complete relations. In this model we assume that the social rankings as well as the individual orderings are complete relations. So, no transitivity or acyclicity condition is imposed on neither the individual orderings nor on the social ranking. It appears that complete relations can be represented by points in a lattice in a Euclidean Space, where the distance between two relations is equal to the lattice-distance of their corresponding lattice points. Therefore, the preferences over the social rankings are single peaked. It means that there is a single best (lattice) point and that preference decreases when the (lattice) distance to this point increases. There is a whole strand of literature on collective decision rules when the individual preferences are single peaked on a Euclidean Space. Without being complete see e.g. Black [1948], Moulin [1980], Border and Jordan [1983], Kim and Roush [1984], Barberà and Peleg [1990], Barberà, Gul and Stacchetti [1993], Barberà, Massó and Neme [1992] and Peters, v.d. Stel and Storcken [1992]. A well-known result is that taking the coordinate-wise medians of the individual optima, eventually supplemented with some fixed "phantom" optima, yields a strategy-proof and unanimous collective decision rule. In various papers it is shown that for specific (sub)sets of single peaked preferences this type of collective decision rule is the only decision rule which satisfies strategy-proofness and some extra conditions such as unanimity, Pareto-optimality and continuity. Here we will prove that the coordinatewise veto rules which form a slightly more general class of rules than the coordinatewise median rules are the only collective decision rules which 
are strategy-proof and non-imposed. An important step in this analysis is that strategyproofness and non-imposedness imply independence of irrelevant alternatives. In this setting this well-known property boiles down to coordinatewiseness. Furthermore, it is shown that in this setting the coordinatewise veto preference rule is actually a so called binary game in constitutional form and resembles voting by committees where suspension is allowed. In Barberà, Sonnenschein and Zhou [1991] voting by committees is analysed. There for every alternative $x$ there is a monotonic simple game of winning coalitions, meaning that $x$ is chosen if, and only if, the voters for $x$ form such a winning coalition. Hence, there suspending $x$ equals rejection of $x$. Here, however, the voting is about the preference between two alternatives, in which indifferences are allowed. Interpreting indifference neither as rejecting nor as accepting alternatives, hence suspension of the decision, it is clear that the decision rule is just a refinement of voting by committees. In fact, by adding a set of blocking coalitions to every set of winning coalitions it is possible to describe these coordinatewise veto preference rules by voting by committees.

Binary games in constitutional form describe decisiveness power of a coalition over all ordered pairs of alternatives at a given preference rule. To every ordered pair $<a, b>$ of alternatives a set of winning coalitions is assigned, meaning that if such a coalition unanimously strictly prefers $a$ to $b$ then collectively $a$ is strictly preferred to $b$. Hence, for each pair <a,b> of alternatives we have a simple game. This notion can be traced back to Bloomfield [1976]. But others have also used simple games in order to describe these decisiveness powers of collective decision rules, see e.g. Peleg [1978] and [1984], Nakamura [1979], Moulin [1985], Le Breton [1987], Andjiga and Moulen [1988] and Trouchon [1993] to cite only a few. It is clear that this description is only useful if the preference rule is independent of irrelevant alternatives. Furthermore, for arbitrary preference rules which satisfy this independence condition it is not required that the simple games are monotonic, i.e. if $S$ is winning then $T$ is winning for $S \subset T$. However, here as in Barberà, Sonnenschein and Zhou [1991], these games are monotonic. Therefore we call this type of preference rule voting by committees. Here we also want to point out that the complement of a set of losing coalitions over a pair <a,b> is the set of coalitions which can block the strict preference: a strictly preferred to $\mathrm{b}$. Therefore, this latter set is called the set of blocking coalitions. It completely determines the set of winning coalitions. For some pairs $<a, b>$, instead of the set of winning coalitions the set of blocking coalitions is used. 
In Barberà, Gul and Stacchetti [1993] as well as in Barberà, Massó and Neme [1992] models with single peaked preferences on a network are considered. Although parts of their results coincide with parts of the results here it seems not possible to exploit their results here because of some basic differences in the assumptions underlying the model. We will come to that at the end of section 3 .

The second set of orderings under consideration is the set of complete and acyclical relations also called the set of acyclic relations. These relations form a (sub)network of the lattice of complete relations. Nevertheless, it is shown that a collective decision rule is independent of irrelevant alternatives, if we add an extra condition called indifference monotonicity to the two already imposed before, i.e. strategy-proofness and unanimity. It follows that these rules are also coordinatewise median rules. Finally, we characterize all coordinatewise median rules which yield acyclic outcomes only. In literature many characterizations of social welfare functions satisfying the independence of irrelevant alternatives, Pareto-optimality and eventually some extra conditions, yielding acyclic relations can be found. Without intending to be exhaustive see e.g. Blair and Pollack [1982], Mas-Colell and Sonnenschein [1972], Brown [1975], Blau and Deb [1977], Kelsey [1985], Moulin [1985] and Trouchon [1993]. In fact our characterization presented here is similar to Trouchon [1993].

The organization of this paper is as follows. In section 2 we define the model and provide some basic notions and results. In section 3 we characterize all non-imposed and strategy-proof preference rules. Finally, in section 4 we discuss non-imposed, strategy-proof and indifference monotonic rules which assign an acyclic ranking to every profile of individual acyclic preferences. 


\section{§ 2. Definitions and Preliminary Results}

Throughout this paper $A$ is the finite and nonempty set of alternatives and $\mathrm{N}=\{1,2, \ldots, \mathrm{n}\}$ the finite and nonempty set of individuals. Let $\mathbf{C}$ be the set of complete and therefore reflexive relations on $A$. Let $R$ be a relation in $\mathbf{C}$. Let $x, y \in A$. Then $<\mathrm{X}, \mathrm{y}>\in \mathrm{R}$ is interpreted as $\mathrm{x}$ is at least as good as $\mathrm{y}$ at relation $\mathrm{R}$. The asymmetric part of $R$ is denoted by $\alpha R$. Consequently $<x, y>\in \alpha R$ means that $x$ is strictly preferred to $y$ at relation $R$. The symmetric part of $R$ is denoted by $\sigma R$. If $<x, y>\in \sigma R$, then we say that $x$ and $y$ are indifferent at relation $R$. The relation $R$ is acyclic if for all $x_{1}, x_{2}, \ldots, x_{k} \in A$, such that $\left.\left\langle\mathrm{x}_{1}, \mathrm{x}_{2}\right\rangle,<\mathrm{x}_{2}, \mathrm{x}_{3}\right\rangle,\left\langle\mathrm{x}_{3}, \mathrm{x}_{4}>\ldots<\mathrm{x}_{\mathrm{k}-1}, \mathrm{x}_{\mathrm{k}}\right\rangle \in \alpha \mathrm{R}$, we have that $\left.4 \mathrm{x}_{\mathrm{k}} \mathrm{x}\right\rangle \in \mathrm{R}$. The set of complete and acyclic relations on $A$ is denoted by $\mathbf{A}$. Clearly we have the following inclusion $\mathbf{A} \subset \mathbf{C}$. Let $\mathbf{C}^{\mathrm{N}}$ and $\mathbf{A}$ be sets of preference profiles $\mathrm{p}$ which assign respectively a complete or complete and acyclic relation $p(i)$ to each individual $i \in N$. So, if $p \in \mathbf{A}^{\mathrm{N}}$, then $p$ is a function from $N$ to $\mathbf{A}$ and $p(1)$ up to $p(n)$ are acyclic. $\mathbf{A}$ preference rule or social welfare function is a mapping $\mathrm{F}$ from $\mathbf{C}^{\mathrm{N}}$ to $\mathbf{C}$. It is an aggregation mechanism assigning a complete relation $F(p)$ to every possible combination of individual complete relations $p \in \mathbf{C}^{\mathrm{N}}$. An acyclic preference rule is a mapping $\mathbf{F}$ from $\mathbf{A}^{\mathrm{N}}$ to $\mathbf{A}$ with a similar interpretation.

Next we will discuss a metric on $\mathbf{C}$, which then is also a metric on A.By virtue of this metric we are able to define strategy-proofness for preference rules. Let $X \Delta Y$ denote the symmetric difference between set $X$ and set $Y$. So, $X \triangle Y:=(X-Y) \cup(Y-X)$, where $X-Y=\{X \in X \mid X \notin Y\}$. Denote the cardinality of a set $X$ by \#X. Let $R^{1}$ and $R^{2}$ be complete relations in $C$. The distance between $R^{1}$ and $R^{2}$, denoted by $\delta\left(R^{1}, R^{2}\right)$, is equal to the cardinality of the symmetric difference between $R^{1}$ and $\mathrm{R}^{2}$. So,

$$
\delta\left(R^{1}, R^{2}\right):=\#\left(R^{1} \Delta R^{2}\right) .
$$

It is straightforward to prove that $\delta$ is a distance function on C. Bogart [1973] shows that $\delta$ is a distance function on the set of quasi-transitive orderings. In fact Kemeny and Snell [1962] introduced this distance function for complete and transitive relations. Hence, the distance function defined here is just an extension of that of Kemeny and Snell [1962]. Therefore it is also referred to as the Kemeny distance. Other authors have also discussed this distance see e.g. Farkas and Nitzan [1979], Campbell and Nitzan [1986], Kendall [1970] and Baigent [1987]. For other approaches 
see e.g. Stehling [1978] and Lerer and Nitzan [1985].

In Bossert and Storcken [1992] strategy-proofness is defined by virtue of the distance function $\delta$. Here we follow the same approach. For a non-empty subset $S$ of $\mathrm{N}$ and a profile $\mathrm{p} \in \mathbf{C}^{\mathrm{N}}$ the restriction of $\mathrm{p}$ to $\mathrm{S}$ is denoted by $\left.\mathrm{p}\right|_{\mathrm{S}}$. A preference rule $\mathrm{F}$ from $\mathbf{C}^{\mathrm{N}}$ to $\mathbf{C}$ is said to be (strictly) strategy-proof if for all individuals i in $\mathrm{N}$ and all profiles $\mathrm{p}$ and $\mathrm{q}$ in $\mathbf{C}^{\mathrm{N}}$ such that $\left.\mathrm{p}\right|_{\mathrm{N}-\{i\}}=\left.\mathrm{q}\right|_{\mathrm{N}-\{i\}}$ and $\mathrm{F}(\mathrm{p}) \neq \mathrm{F}(\mathrm{q})$

$$
\delta(p(i), F(p))<\delta(p(i), F(q)) \text {. }
$$

In words, strict strategy-proofness means that deviations by a single individual i from a profile $p$ yield outcomes which are either the same as at $p$ or are strictly worser than that at $p$ for that individual $i$. Here, of course, a social ranking $F(p)$ is preferred to another different ranking $F(q)$ if the distance from i's preference $p(i)$ to $F(p)$ is smaller than that to $F(q)$. In Bossert and Storcken [1992] strategy-proofness is defined for coalitions on linear preference orderings such that the strict inequality at (1) is replaced by a weak inequality " $\leq$. Furthermore, their results seem to hold even for a weaker strategy-proofness condition, namely intermediate strategy-proofness. This latter condition (discussed later) is equivalent to strategy-proofness (with " $\leq "$ ). Therefore, it is fair to say that here we use a slightly stronger condition than actually needed in Bossert and Storcken [1992]. Essentially, we changed a weak inequality in a strict inequality. This at first sight minor change is of vital importance, because with the weaker strategy-proofness condition we were not able to prove lemma 2.5 and 2.6, which form the basic ingredient of the rest of the proofs.

As mentioned before (strict) strategy-proofness is equivalent to intermediate (strict) strategy-proofness. The latter condition means that a unanimous coalition cannot benefit by deviating. Formally, a preference rule $\mathrm{F}$ from $\mathbf{C}$ to $\mathbf{C}^{\mathrm{N}}$ is intermediate (strictly) strategy-proof if for all coalitions $S \subset N, S \neq \varnothing$, all $R \in \mathbf{C}$ and all profiles $p, q \in \mathbf{C}^{\mathrm{N}}$ such that $\left.p\right|_{N-S}=\left.q\right|_{N-S}, F(p) \neq F(q)$ and $p(i)=R$ for all $i \in S$ we have

$$
\delta(R, F(p))<\delta(R, F(q)) \text {. }
$$

Intermediate (strictly) strategy-proofness was introduced by Peters, v.d. Stel and Storcken [1992]. Clearly, by taking $S=\{i\}$, intermediate (strict) strategy-proofness implies (strict) strategy-proofness. The reverse implication also holds. The proof of this is treated in the following lemma. It is an adaptation of lemma 2.4 of the latter reference to the model here. 
LEMMA 2.1 Let $\mathrm{F}: \mathbf{C}^{\mathrm{N}} \rightarrow \mathbf{C}$ be a preference rule. Then (i) and (ii) are equivalent, where: $\quad$ (i) $\quad F$ is strictly strategy-proof, and

(ii) $\mathrm{F}$ is intermediate strictly strategy-proof.

PROOF The implication (ii) $\Rightarrow$ (i) is evident. For the converse let $S \subset N, S \neq \varnothing$, $R \in \mathbf{C}, p, q \in \mathbf{C}^{N}$, such that $p(i)=R$ for all $i \in S$, and $\left.p\right|_{N-S}=\left.q\right|_{N-S}$. Without loss of generality suppose $S=\{1,2, \ldots, s\}$. Take $\mathrm{p}^{0}, \mathrm{p}^{1}, \ldots, \mathrm{p}^{\mathrm{s}} \in \mathbf{C}^{\mathrm{N}}$ such that for all $\mathrm{i} \in \mathrm{N}$ and

$$
p^{t}(i)=\left\{\begin{array}{l}
p(i) \text { if } t<i \\
q(i) \text { if } t \geq i
\end{array}\right.
$$

Hence $p^{0}=p$ and $p^{s}=q$. By strictly strategy-proofness it follows for all $i \in S$ :

$F\left(p^{i-1}\right)=F\left(p^{i}\right)$ or $\delta\left(R, F\left(p^{i-1}\right)\right)<\delta\left(R, F\left(p^{i}\right)\right)$.

Hence, $F(p)=F(q)$ or $\delta(R, F(p))<\delta(R, F(q))$.

From now on by strategy-proofness is meant strictly strategy-proofness as well as intermediate strictly strategy-proofness. Furthermore, strategy-proofness can be defined in an obvious way for acyclic preference rules. Therefore we will use this condition without further specification.

There is a geometrical nice way to represent the metric space $(\mathbf{C}, \bar{\delta})$. We will describe this representation hereafter. Let $A=\left\{a_{1}, \ldots, a_{m}\right\}$. Then there are $M:=1 / 2 m(m-1)$ tuples of the kind $\left\{a_{i}, a_{j}\right\}$ with $i \neq j$. Consider the M-dimensional Euclidean space $\mathbb{R}^{\mathrm{M}}$. Assign to each tuple $\left\{\mathrm{a}_{\mathrm{i}}, \mathrm{a}_{\mathrm{i}}\right\}$ with $\mathrm{i}<\mathrm{j}$ a coordinate axis, such that different tuples are assigned to different coordinate axes. To avoid extra variables coordinates are not as usual indicated by one number but by a pair. For instance ij, where $1 \leq \mathrm{i} \leq \mathrm{j} \leq \mathrm{m}$, indicates the coordinate axis assigned to the tuple $\left\{\mathrm{a}_{\mathrm{i}}, \mathrm{a}_{\mathrm{j}}\right\}$. Furthermore, $e_{i j}$ is the vector whose $\mathrm{ij}^{\text {th }}$ coordinate is equal to one and all its others are zero. So, $\left\{e_{i j} \mid 1 \leq i \leq j \leq m\right\}$ is a standard basis of $\mathbb{R}^{M}$.

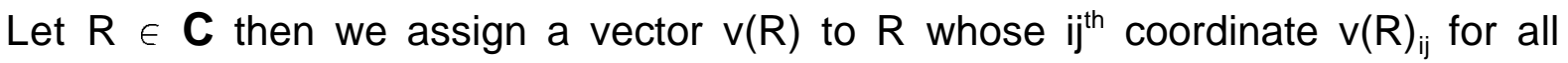
$1 \leq \mathrm{i} \leq \mathrm{j} \leq \mathrm{m}$ is defined as follows.

$$
v(R)_{i j}=\left\{\begin{array}{cl}
1 & \text { if }<a_{i}, a_{j}>\in \alpha R, \\
0 & \text { if }<a_{i}, a_{j}>\in \sigma R, \text { and } \\
-1 & \text { if }<a_{i}, a_{i}>\in \alpha R .
\end{array}\right.
$$

So, $v(R)=\sum^{m=1} \sum_{j p i+1} v(R)_{i j} e_{i j}$.

Of course every relation $R$ has its unique vector representation $v(R)$ in $\mathbb{R}^{M}$. For instance 
consider $\mathrm{I}:=\mathrm{A} \times \mathrm{A} \in \mathbf{C}$ (the total indifference). Clearly $\mathrm{v}(\mathrm{I})=\langle 0,0, \ldots, 0\rangle$ is the nil vector in $\mathbb{R}^{\mathrm{M}}$. Moreover, every vector $\mathrm{v}$ in $\{1,0,-1\}^{\mathrm{M}}$ corresponds to a relation $\mathrm{R}$ in $\mathbf{C}$ such that $v=v(R)$. For instance, $e_{i j}=v\left(E_{i j}\right)$ where $E_{i j}=A \times A-\left\{<a_{,}, a>\right\}$ for all $1 \leq i<j \leq m$. Let $-E_{i j}=A \times A-\left\{<a_{i}, a_{j}>\right\}$ for all $1 \leq i<j \leq m$. Then $v\left(-E_{i j}\right)=-e_{i j}$. Clearly $\{-1,0,1\}^{\mathrm{M}}$ can be seen as a lattice. Because for all $R^{1}, R^{2} \in C$

$$
\delta\left(R^{1}, R^{2}\right)=\sum^{m=1} \sum_{j \mathrm{ji+1}}^{m} \mid v\left(R_{1}\right)_{i j}-v\left(R_{2}\right) \text { ij } \mid,
$$

it follows that $\delta\left(R^{1}, R^{2}\right)$ is equal to the lattice distance between the corresponding lattice points.

Now we formulate several conditions for preference rules. Then we end this section by developing some consequences of strategy-proofness of preference rules.

Let $\mathrm{F}$ from $\mathbf{C}^{\mathrm{N}}$ to $\mathbf{C}$ be a preference rule. Then $\mathrm{F}$ is said to be non-imposed if for all $\mathbf{R} \in \mathbf{C}$ there is a profile $p \in \mathbf{C}^{N}$ such that $F(p)=R$. This surjectivity condition is wellknown and needs no further discussion just as the following unanimity condition. $F$ is unanimous if for all $R \in \mathbf{C} \quad F\left(R^{N}\right)=R$. Here $R^{N}$ is a profile where every individual has preference $R$. Similarly, for $S \subset N, R^{S}$ is a profile in $C^{S}$ such that all individuals in $S$ have preference $R$.

Let $R^{1}, R^{2}, R^{3} \in C$. Then $R^{2}$ is between $R^{1}$ and $R^{3}$ if $\left(R^{1} \cap R^{3}\right) \subset R^{2} \subset\left(R^{1} \cup R^{3}\right)$. It is straightforward to prove the following lemma which can also be found in for instance Bogart [1973], Mirkin [1979] and Barthélemy and Monjardin [1981]; therefore it is stated without proof. The lemma identifies the cases where the triangle inequality is equality. 
LEMMA 2.2 Let $R^{1}, R^{2}, R^{3} \in \mathbf{C}$ then (i) and (ii) are equivalent where:

(i) $\quad R^{2}$ is between $R^{1}$ and $R^{3}$

(ii) $\quad \delta\left(R^{1}, R^{3}\right)=\delta\left(R^{1}, R^{2}\right)+\delta\left(R^{2}, R^{3}\right)$.

A preference rule $F$ from $\mathbf{C}^{N}$ to $\mathbf{C}$ is said to be monotonic if for all profiles $p, q \in \mathbf{C}^{N}$ such that for all $i \in N \quad q(i)$ is between $p(i)$ and $F(p)$ it follows that $F(p)=F(q)$. Monotonicity means that changes towards the outcome have no effect.

The following condition is Arrow's well-known independence condition,see e.g. Arrow [1963]. A preference rule $F$ from $\mathbf{C}^{N}$ to $\mathbf{C}$ is said to be independent of irrelevant alternatives if for all $x, y \in A$ and all $p, q \in \mathbf{C}^{N}$ such that for all $i \in N$

$<\mathrm{x}, \mathrm{y}>\in \mathrm{p}(\mathrm{i}) \Leftrightarrow<\mathrm{x}, \mathrm{y}>\in \mathrm{q}(\mathrm{i})$ and

$<y, x>\in p(i) \Leftrightarrow<y, x>\in q(i)$, it follows that $<x, y>\in F(p) \Leftrightarrow<x, y>\in F(q)$.

The last condition which is discussed here is a relaxation of the independence of irrelevant alternatives. It says that if individuals change a strict preference over $\mathrm{x}$ and $y$ into an indifference between $x$ and $y$ and all the other pairs are left unchanged, then this change has no effect on the collective indifference between any pair $a$ and $b$ not equal to $x$ and $y$. Hence, indifferences between $a$ and $b$ on the collective level cannot be resolved (into strict preferences) by introducing more indifferences between other pairs on the individual level. A preference rule $\mathrm{F}$ from $\mathbf{C}^{\mathrm{N}}$ to $\mathbf{C}$ is said to be indifference monotonic if, for all $x, y, a, b \in A$, with $\{x, y\} \neq\{a, b\}$, and for all $p, q \in \mathbf{C}^{N}$, such that for all $i \in N$ either $p(i) \cup\{<x, y>,<y, x>\}=q(i)$ or $p(i)=q(i)$, it follows that $<a, b>\in \sigma F(p)$ implies $\langle a, b\rangle \in \sigma F(q)$. Obviously, the independence of irrelevant alternatives implies indifference monotonicity, but clearly not the other way around.

Moreover, the antidictatorial rule which determines the collective preference by reversing all preferences of the antidictator $i$ is a preference rule which is independent of irrelevant alternatives, hence indifference monotonic, and non-imposed. But it is neither strategy-proof, nor unanimous, nor monotonic. An example of a preference rule which is strategy-proof but not independent of irrelevant alternatives is e.g. as follows. Let $\mathrm{R}^{1}=\mathrm{A} \times \mathrm{A}-\left\{<\mathrm{a}_{2}, \mathrm{a}_{1}>,<\mathrm{a}_{3}, \mathrm{a}_{1}>,<\mathrm{a}_{3}, \mathrm{a}_{2}>\right\}$ and $R^{2}=A \times A-\left\{<a_{2}, a_{1}>,<a_{2}, a_{3}>\right\}$. Now define $F: \mathbf{C}^{N} \rightarrow \mathbf{C}$ for all $p \in \mathbf{C}^{N}$ as follows.

$$
F(p)= \begin{cases}R^{1} \text { if } \delta\left(p(1), R^{1}\right)<\delta\left(p(1), R^{2}\right) \\ \quad R^{2} \text { if } \delta\left(p(1), R^{2}\right)<\delta\left(p(1), R^{1}\right) .\end{cases}
$$


Since $\delta\left(R^{1}, R^{2}\right)=3$ and there are only cycles of even length in the lattice it follows straightforwardly that $F$ is well-defined and strategy-proof. Let $p, q \in \mathbf{C}^{N}$ such that $\left.p\right|_{N-\{1\}}=q_{N-\{1\}}, p(1)={ }_{1}$ and $q(1)=I$. Ther sa $, a>\in \sigma p(1), z_{3} a, a>\in \sigma q(1)$, $<\mathrm{a}_{2}, \mathrm{a}_{3}>\in \alpha \mathrm{F}(\mathrm{p})=\alpha \mathrm{R}^{1}$ and $<\mathrm{a}_{3}, \mathrm{a}_{\mathrm{2}}>\in \alpha \mathrm{F}(\mathrm{q})=\alpha \mathrm{R}$. Hence, $\mathrm{F}$ is not independent of irrelevant alternatives.

In the following section it is proved that non-imposed and strategy-proof preference rules are independent of irrelevant alternatives. Furthermore, if we adapt the conditions stated above to acyclic preference rules, then in the last section it is proved that for non-imposed and strategy-proof acyclic preference rules independence of irrelevant alternatives is equivalent to indifference monotonicity. This clarifies several of the logical relations between the various conditions introduced above, but not all. For instance it is not clear whether there exist strategy-proof and indifference monotonic acyclic preference rules which are not independent of irrelevant alternatives. The following lemma is an analogon of Lemma 3.1 in Peters, v.d. Stel and Storcken [1992].

LEMMA 2.3 Let $\mathrm{F}$ be a strategy-proof preference rule. Then $\mathrm{F}$ is monotonic.

Proof Let $i \in N$ and $p, q \in \mathbf{C}^{N}\left(\mathbf{A}^{N}\right)$ such that $\left.p\right|_{N-\{i\}}=\left.q\right|_{N-\{i\}}$ and $q(i)$ is between $p(i)$ and $F(p)$. It is sufficient to prove that $F(p)=F(q)$.

Suppose $F(p) \neq F(q)$. Then by strategy-proofness we have

$$
\begin{aligned}
& \delta(p(i), F(p))<\delta(p(i), F(q)) \text { and } \\
& \delta(q(i), F(q))<\delta(q(i), F(p)) .
\end{aligned}
$$

Because $q(i)$ is between $p(i)$ and $F(p)$, it follows that

$$
\delta(p(i), q(i))+\delta(q(i), F(p))=\delta(p(i), F(p))
$$

Using (2), (3), (4) and the triangle inequality yields

$$
\begin{aligned}
\delta(\mathrm{p}(\mathrm{i}), \mathrm{F}(\mathrm{q})) & \leq \delta(\mathrm{p}(\mathrm{i}), \mathrm{q}(\mathrm{i}))+\delta(\mathrm{q}(\mathrm{i}), \mathrm{F}(\mathrm{q})) \\
& <\delta(\mathrm{p}(\mathrm{i}), \mathrm{q}(\mathrm{i}))+\delta(\mathrm{q}(\mathrm{i}), \mathrm{F}(\mathrm{p})) \\
& =\delta(\mathrm{p}(\mathrm{i}), \mathrm{F}(\mathrm{p})) \\
& <\delta(\mathrm{p}(\mathrm{i}), \mathrm{F}(\mathrm{q})) .
\end{aligned}
$$

Clearly we have a contradiction. So, $F(p)=F(q)$.

Because for all relations $R^{1}, R^{2} \in C \quad R^{1}$ is between $R^{1}$ and $R^{2}$, by the foregoing lemma 
it follows for strategy-proof preference rules $F$ that for all $p \in \mathbf{C}^{N} F\left((F(p))^{N}\right)=F(p)$. Hence, as a consequence we have the following well-known result (see e.g. Gibbard [1973]).

CORROLARY 2.4 Let $\mathrm{F}$ be a non-imposed and strategy-proof preference rule. Then $F$ is unanimous.

We end this section with two lemmas which are used later on. The following lemma says that for specific profiles the outcome of a preference rule is Pareto-optimal.

LEMMA 2.5 Let $F$ be a non-imposed and strategy-proof preference rule. Let $R_{1}, R_{2}$ and $R_{3}$ be (acyclic and) complete relations on $A$ such thąt $R \Delta R \subset\{<x, y>\}$, $R_{2} \Delta R_{3} \subset\{<y, x>\}, R_{1} \subset R_{2}$ and $R_{3} \subset R_{2}$ for some $x, y \in A$. Let $S, T, U$ be a partition of $N$. Then $F\left(R_{1}{ }^{\mathrm{S}}, \mathrm{R}_{2}{ }^{\top}, \mathrm{R}_{3}{ }^{\mathrm{U}}\right) \in\left\{\mathrm{R}_{1}, \mathrm{R}_{2}, \mathrm{R}_{3}\right\}$.

Furthermore, if $\#\left\{R_{1}, R_{2}, R_{3}\right\}=3$ and $F\left(R_{1}{ }^{S}, R_{2}{ }^{\top \cup U}\right)=R_{1}$, then $F\left(R_{1}{ }^{S}, R_{2}{ }^{\top}, R_{3}{ }^{U}\right)=R_{1}$

PROOF By unanimity it is without loss of generality to suppose that $R_{1} \neq R_{2}$. Hence $\delta\left(R_{1}, R_{2}\right)=1$ and $\delta\left(R_{2}, R_{3}\right) \leq 1$. So, we have the following two situations illustrated by the following two diagrams.

$\mathrm{R}_{1} \stackrel{1}{-} \mathrm{R}_{2}=\mathrm{R}_{3} \quad \mathrm{R}_{1} \longrightarrow \mathrm{R}_{2} \stackrel{1}{-} \mathrm{R}_{3} \quad 1$

Let $F\left(R_{1}{ }^{S}, R_{2}{ }^{\top}, R_{3}{ }^{U}\right)=R_{4}$.

Then by the assumption on $R_{1}, R_{2}$ and ${ }_{3} R$ it follows that there is a relation $R \in\left\{R_{1}, R_{2}, R_{3}\right\}$ such that $R$ is between $R_{4}$ and $R_{i}$ for all $i \in\{1,2,3\}$. So, by monotonicity we have $F\left(R^{N}\right)=R_{4}$. By unanimity it follows that $R=R_{4}$. Hence, $R_{4} \in\left\{R_{1}, R_{2}, R_{3}\right\}$.

The furthermore part now follows straightforwardly by strategy-proofness.

The following lemma appears to be a powerful tool for the subsequent sections. It reads as follows. Let $R_{1}, R_{2}, R_{3}$ and $R_{4}$ be a "square" in the lattice. Let $S$ be a coalition that is decisive at a "side", i.e. $F\left(R_{1}{ }^{S}, R_{2}{ }^{N-S}\right)=R_{1}$. Then $S$ is decisive at the opposite "side", so $F\left(R_{3}{ }^{S}, R_{4}{ }^{N-S}\right)=R_{3}$.

LEMMA 2.6 Let F be a non-imposed and strategy-proof (acyclic) preference rule. Let 
$R_{1}, R_{2}, R_{3}, R_{4}$ be (acyclic) complete relations, such that for some $x, y, a, b \in A$, with $\{x, y\} \neq\{a, b\}, \quad x \neq y$ and $a \neq b, R_{1} \Delta{ }_{2} R=R_{4} \Delta R=\{<x, y>\}$ and $R_{1} \Delta R_{4}=R_{2} \Delta R_{3}=\{<a, b>\}$.

Let $S \subseteq N$ such that $F\left(R_{1}{ }^{S}, R_{2}{ }^{N-S}\right)=R_{1}$. Then $F\left(R_{3}{ }^{S}, R_{4}{ }^{N-S}\right)=R_{3}$.

PROOF Because of the assumption $\delta\left(R_{1}, R_{2}\right)=\delta\left(R_{2}, R_{3}\right)=\delta\left(R_{3}, R_{4}\right)==\delta\left(R_{1}, R_{4}\right)=1$ and $\#\left\{R_{1}, R_{2}, R_{3}, R_{4}\right\}=4$.

Hence, we have the following diagram.

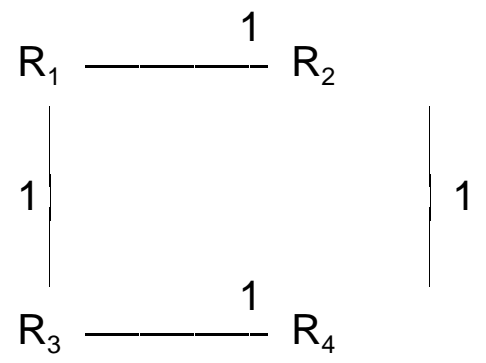

Let $R_{5}:=F\left(R_{3}{ }^{s}, R_{2}{ }^{N-s}\right)$. We distinguish two cases.

Case $1 \quad R_{5} \neq R_{1}$. Then by strategy-proofness we have $\delta\left(R_{5}, R_{3}\right)<\delta\left(R_{7}, R_{3}\right)=1$. Hence, in that case $R_{5}=R_{3}$. So, by monotonicity it follows that $F\left(R_{3}{ }^{S}, R_{4}{ }^{N-S}\right)=R_{3}$.

Case $2 \quad R_{5}=R$. Let $\left.R=F_{6} R^{{ }^{s}}{ }^{n}{ }^{N-S}\right)$. By strategy-proofness it follows that $R_{6} \neq R_{4}$. Since by lemma $2.5 R_{6} \in\left\{R_{3}, R_{4}\right\}$ it follows that $R_{6}=R_{3}$.

The relations $R_{1}, R_{2}, R_{3}$ and $R_{4}$ as defined in the previous lemma form a "square" in the lattice. These play an important rôle later on, therefore we will refer to these 4 points/relations by elementary square. 


\section{§ 3. VOTING BY COMMITTEES}

In this section we characterize all strategy-proof and non-imposed preference rules $\mathrm{F}$ from $\mathbf{C}^{\mathrm{N}}$ to $\mathbf{C}$. First we show that the coordinatewise veto rules, a generalization of the coordinatewise median rule, coincide with voting by comittees. These rules appear to be non-imposed and strategy-proof. Then we show that non-imposed and strategyproof preference rules are independent of irrelevant alternatives. Hence, they are coordinatewise. By this it is shown that these preference rules are voting by committees.

A (monotonic) simple game is a pair $\langle\mathrm{N}, \mathrm{W}>$ such that $\mathrm{W}$ is a subset of the powerset of $\mathrm{N}, \varnothing \notin \mathrm{W}, \mathrm{N} \in \mathrm{W}$ and for all $\mathrm{S}, \mathrm{T} \subset \mathrm{N}$, with $\mathrm{S} \subset \mathrm{T}, \mathrm{S} \in \mathrm{W}$ implies $\mathrm{T} \in \mathrm{W}$. The set $\mathrm{W}$ consists of all winning coalitions. Simple games are well-known in game theory and social choice theory they have many applications see e.g. Peleg [1978] and [1984], Barberà, Sonnenschein and Zhou [1991] and Ramamurthy [1990]. A preference rule $F$ from $\mathbf{C}^{\mathrm{N}}$ to $\mathbf{C}$ is said to be voting in committees (see also Barberà, Sonnenschein and Zhou [1991], Bloomfield [1976] and Trouchon [1993]) if for all $1 \leq \mathrm{i}<\mathrm{j} \leq \mathrm{m}$ there are simple games $<N, W_{i j}>$ and $<N, B_{i j}>$ such that $W_{i j} \subset B_{i j}$ and for all profiles $p \in C^{N}$

$$
v(F(p))_{i j}:=\left\{\begin{array}{cl}
-1 & \text { if }\left\{t \in N \mid p(t)_{i j}=-1\right\} \in W_{i j} \\
0 & \text { if }\left\{t \in N \mid p(t)_{i j}=-1\right\} \notin W_{i j} \text { and }\left\{t \in N \mid p(t)_{i j} \leq 0\right\} \in B_{i j} \\
1 & \text { if }\left\{t \in N \mid p(t)_{i j} \leq 0\right\} \notin B_{i j}
\end{array}\right.
$$

Indicating such a collection of simple games by $w$, such a preference rule is denoted by $F_{w}$. So, $<a_{2}, a_{1}>\in \alpha F_{w}(p)$ if the coalition of individuals strictly preferring $a_{2}$ to $a_{1}$ at $p$, i.e. $\left\{t \in N \mid p(t)_{12}=-1\right\}$, is winning in simple game $<N, W_{12}>$. Interpreting coalitions in $\mathrm{B}_{\mathrm{ij}}$ as blocking coalitions we obtain $<\mathrm{a}_{2}, \mathrm{a}_{1}>\in \sigma \mathrm{F}(\mathrm{p})$ if the coalition of individuals strictly preferring $\mathrm{a}_{2}$ to $\mathrm{a}_{1}$ is not winning in game $<\mathrm{N}, \mathrm{W}>$ and the coalition of individuals weakly preferring $a_{2}$ to $a_{1}$ is blocking i.e. winning in game $<N, B_{12}>$. If this latter coalition is not blocking, then $<a_{1}, a_{2}>\in \alpha F(p)$.

A map $\lambda$ from $2^{\mathrm{N}}$, the powerset of $\mathrm{N}$ to $\{-1,0,1\}^{\mathrm{M}}$ is an assignment of disagreements if for all $1 \leq \mathrm{i}<\mathrm{j} \leq \mathrm{m}$ and all $\mathrm{S} \subset \mathrm{T} \subset \mathrm{N}, \lambda(\mathrm{N})_{\mathrm{ij}}=-1, \lambda(\varnothing)_{\mathrm{ij}}=1$ and $\lambda(\mathrm{S})_{\mathrm{ij}}>\lambda(\mathrm{T})_{\mathrm{ij}}$. A preference rule $F$ from $C^{N}$ to $\mathbf{C}$ is coordinatewise veto voting if there is an assignment of disagreements $\lambda$ such that for all $1 \leq i<j \leq M$ and all profiles $p \in \mathbf{C}^{N}$

$$
v(F(p))_{i j}=\min _{S \subset N} \max \left(\left\{v(p(t))_{i j} \mid t \in S\right\} \cup\left\{\lambda(S)_{i j}\right\}\right) .
$$

These rules were introduced by Border and Jordan [1983]. Having an assignment of 
disagreements $\lambda$ the corresponding coordinatewise veto voting preference rule is denoted by $F_{\lambda}$.

Consider a profile $\mathrm{p}$ and a coordinate $\mathrm{ij}$, such that $\mathrm{v}(\mathrm{p}(\mathrm{t}))_{\mathrm{ij}}=-1$ for all $\mathrm{t} \in \mathrm{S}$ and $v(p(t))_{i j}=+1$ for all $t \in N-S$, for some coalition $S$. Then $x(F(p))=\lambda_{j}(S)$. So, at a maximal conflict between $S$ and $N-S$ over the preference between $a_{i}$ and $a_{j}, \lambda(S)_{i j}$ is the outcome. In some sence $\lambda(s)_{i j}$ indicates the decision power of $S$ over the pair of alternatives $a_{i}$ and $a_{j}$.

For an arbitrary profile $p$ and an arbitrary coalition $S$, by the definition of $F_{\lambda}$ it follows that $v\left(F_{\lambda}(p)\right)_{i j} \leq \max \left(\left\{v(p(t))_{i j} \mid t \in S\right\} \cup\left\{\lambda\left(S_{\lambda j}\right\}\right)\right.$ for all coordinates ij. So, $S$ can veto all points greater than this maximum with respect to coordinate ij.

For example, let $v(p(n))_{i j} \leq v(p(n-1))_{i j} \leq \ldots \leq v(p(2))_{j} \leq v(p(1))_{j}$. Let $S_{\delta}=\varnothing, S=\{1\}$, $S_{2}=\{1,2\}, \quad \ldots n$ and $S={ }_{\lambda} N_{\cdot i j}$ Then $v(F(p))$ is the median of $\left\{v(p(n))_{i j}, v(p(n-1))_{i j}, \ldots, v(p(1))_{i j}, \lambda\left(S_{0}\right)_{i j}, \ldots, \lambda\left(S_{n}\right)_{i j}\right\}$.

Special choices of $\lambda$ yield interesting subclasses of the class of coordinatewise veto voting. For instance, the dictatorial rule with dictator 2 is obtained in the following way

$$
\lambda(S)_{i j}=\left\{\begin{array}{ccc}
-1 & \text { if } & 2 \in S \text {, and } \\
1 & \text { if } & 2 \notin S .
\end{array}\right.
$$

An absolute pairwise majority rule, at which a strict preference between two alternatives myst be supported by more than half of the polulation (all other cases yield

$$
\lambda(S)_{i j}=\left\{\begin{array}{ccc}
-1 & \text { if } \# S>\# N-S \\
0 & \text { if } \# S=\# N-S \\
1 & \text { if } \# S<\# N-S .
\end{array}\right.
$$

For more explanation see e.g. Peters, v.d. Stel and Storcken [1991].

Let $\mathrm{w}$ be a collection of simple games $\left\langle\mathrm{N}, \mathrm{W}_{\mathrm{ij}}>\right.$ and $<\mathrm{N}, \mathrm{B}_{\mathrm{ij}}>$ for all $1 \leq \mathrm{i}<\mathrm{j} \leq \mathrm{M}$ as above. Now define $\lambda_{w}$ an assignment of disagreements for all $S \subset N$ as follows.

For all $1 \leq \mathrm{i}<\mathrm{j} \leq \mathrm{M}$ 


$$
\lambda_{w}(S)_{i j}:=\left\{\begin{array}{cl}
-1 & \text { if } S \in W_{i j} \\
0 & \text { if } S \in B_{i j}-W_{i j} \\
1 & \text { if } S \notin B_{i j}
\end{array}\right.
$$

So, $v\left(F_{w}(p)\right)_{i j}=\lambda_{w}(S)_{i j}$ if $S=\left\{t \in N \mid<a_{j}, a_{i}>\in \alpha p(t)\right\}$ and $N-S=\left\{t \in N \mid<a_{i}, a_{j}>\in \alpha p(t)\right\}$. Because for all $1 \leq \mathrm{i}<\mathrm{j} \leq \mathrm{M} \varnothing \notin \mathrm{B}_{\mathrm{ij}}, \mathrm{N} \in \mathrm{W}_{\mathrm{ij}}, \mathrm{W}_{\mathrm{ij}} \subset \mathrm{B}_{\mathrm{j}}$ and $<\mathrm{N}, \mathrm{W}_{\mathrm{j}}>$ and $<\mathrm{N}, \mathrm{B}>$ are monotonic, it follows that $\lambda_{w}$ is an assignment of disagreements.

Moreover, by the following lemma it follows that $F_{\lambda_{w}}=F_{w}$.

LEMMA 3.1 Let $1 \leq \mathrm{i}<\mathrm{j} \leq \mathrm{m}$ and $\mathrm{p} \in \mathbf{C}^{\mathrm{N}}$.

Then $v\left(F_{\lambda_{w}}(p)\right)_{i j}=v\left(F_{w}(p)\right)_{i j}$.

ProOF Let $S=\left\{t \in N \mid p(t)_{i j}=-1\right\}$ and $T=\left\{t \in N \mid p(t)_{i j} \leq 0\right\}$.

We distinguish three cases.

Case $1 \quad v\left(F_{w}(p)\right)_{i j}=-1$. Then by definition $S \in W_{i j}$.

Hence, $\max \left(\left\{v(p(t))_{i j} \mid t \in S\right\} \cup\left\{\lambda_{w}(S)_{i j}\right\}\right)=-1$. So, $v\left(F_{\lambda_{w}}(p)\right)_{i j}=-1$.

Case $2 \quad v\left(F_{w}(p)\right)_{i j}=0$. Then by definition $S \notin W_{i j}$ and $T \in B_{i j}$.

Hence, $\max \left(\left\{v(p(t))_{i j} \mid t \in T\right\} \cup \lambda_{w}(T)_{i j}\right) \leq 0$. So, $v\left(F_{\lambda_{w}}(p)\right)_{i j} \leq 0$.

If $\mathrm{v}\left(\mathrm{F}_{\lambda_{\mathrm{w}}}(\mathrm{p})\right)_{\mathrm{ij}}=-1$, then by definition there is a subset $\mathrm{X} \subset \mathrm{N}$ such that $\max \left(\left\{v(p(t))_{i j} \mid t \in X\right\} \cup \lambda_{w}(X)_{i j}\right)=v\left(F_{\lambda_{w}}(p)\right)_{i j}=-1$. In that case $X \subset S$ and $\lambda_{w}(X)=-1$. This however, is not possible. Therefore, $v\left(F_{\lambda_{w}}(p)\right)_{i j}=0$.

Case $3 \quad v\left(F_{w}(p)\right)_{i j}=1$. If $v\left(F_{\lambda_{w}}(p)\right)_{j} \leq 0$, then it follows that for some $X \in{ }_{i j} B$ max $\left(\left\{v(p(t))_{i j} \mid t \in X\right\} \cup\left\{\lambda_{w}(X)_{i j}\right\}\right) \leq 0$. Hence, $X \subseteq T$. This however, cannot be the case. So $\mathrm{v}\left(\mathrm{F}_{\lambda_{\mathrm{w}}}(\mathrm{p})\right)_{\mathrm{ij}}=1$.

So, every voting by committees preference rule is in fact a coordinatewise veto voting preference rule. In order to show the reverse let $\lambda$ be an assignment of disagreements. For all $1 \leq \mathrm{i}<\mathrm{j} \leq \mathrm{M}$ and all $\mathrm{S} \subset \mathrm{N}$ let $\mathrm{W}_{\mathrm{ij}}^{\lambda}$ and $\mathrm{B}_{\mathrm{ij}}^{\lambda}$ be defined as follows:

$$
\begin{array}{ll}
S \in W_{i j}^{\lambda} \text { and } S \in B_{i j}^{\lambda} & \text { if } \lambda(S)_{i j}=-1, \\
S \notin W_{i j}^{\lambda} \text { and } S \in B_{i j}^{\lambda} & \text { if } \lambda(S)_{i j}=0, \text { and } \\
S \notin W_{i j}^{\lambda} \text { and } S \notin B_{i j}^{\lambda} & \text { if } \lambda(S)_{i j}=1 .
\end{array}
$$

Clearly $\mathrm{W}_{\mathrm{ij}}^{\lambda} \subset \mathrm{B}_{\mathrm{ij}}^{\lambda}, \mathrm{N} \in \mathrm{W}_{\mathrm{ij}}^{\lambda}, \varnothing \notin \mathrm{B}_{\mathrm{j}}^{\lambda}$ and for all $\mathrm{S} \subset \mathrm{T} \quad \mathrm{S} \in \mathrm{W}_{\mathrm{j}}$ implies $\mathrm{T} \in \mathrm{W}_{\mathrm{j}}^{\lambda}$ and $\mathrm{S} \in \mathrm{B}^{\mathrm{B}}$ implies $T \in B_{i j}^{\lambda}$. Let $w_{\lambda}$ denote the collection of all simple games corresponding to these sets $W_{i j}^{\lambda}$ and $B_{i j}^{\lambda}$. The following lemma shows that $F_{\lambda}=F_{W_{\lambda}}$. 
LEMMA 3.2 Let $1 \leq \mathrm{i}<\mathrm{j} \leq \mathrm{m}$ and $\mathrm{p} \in \mathbf{C}^{\mathrm{N}}$.

Then $v\left(F_{\lambda}(p)\right)_{i j}=v\left(F_{w_{\lambda}}(p)\right)_{i j}$.

ProOF Let $S=\left\{t \in N \mid v(p(t))_{i j}=-1\right\}$ and $T=\left\{t \in N \mid v(p(t))_{i j} \leq 0\right\}$.

Let $\mathrm{X}$ be a subset in $\mathrm{N}$ such that

$$
v\left(F_{\lambda}(p)\right)_{i j}=\max \left(\left\{v(p(t))_{i j} \mid t \in X\right\} \cup\left\{\lambda(x)_{i j}\right\}\right) .
$$

We distinguish three cases. Without loss of generality suppose $S \subset X$.

Case $1 V\left(F_{\lambda}(p)\right)_{i j}=-1$. Then $X=S$ and $\lambda(X)_{i j}=-1$. So, $\lambda(S)_{i j}=-1$ and $S \in W_{i j}^{\lambda}$. Hence, $v\left(F_{w_{\lambda}}(p)\right)_{i j}=-1$.

Case $2 \quad v\left(F_{\lambda}(p)\right)_{i j}=0$. Then $\lambda(S)_{i j} \geq 0$. Hence, $S \notin W_{i j}^{\lambda}$.

Furthermore, $\mathrm{X} \subset \mathrm{T}$ and $\lambda(\mathrm{X})_{\mathrm{ij}} \leq 0$. Hence, $\mathrm{X} \in \mathrm{B}_{\mathrm{ij}}^{\lambda}$. So, $\mathrm{T} \in \mathrm{B}_{\mathrm{ij}}^{\lambda}$.

Now $v\left(F_{w_{\lambda}}(p)\right)_{i j}=0$, because $S \notin W_{i j}$ and $T \in B_{i j}$.

Case $3 \quad v\left(F_{\lambda}(p)\right)_{i j}=1$. Then there is no subset $Y$ of $N$ such that $Y \subset T$ and $\lambda(Y)_{i j} \leq 0$. Hence, $\lambda(T)_{i j}=1$. So, $T \notin B_{i j}^{\lambda}$ and $v\left(F_{w_{\lambda}}(p)\right)_{i j}=1$.

Combining the previous two lemmas yields

CORROLARY 3.3 Every voting by committees preference rule is a coordinatewise veto voting preference rule and vice versa.

The following result is straightforward see e.g. Barberà, Gul and Stacchetti [1993] or Border and Jordan [1983].

LEMMA 3.4 Every coordinatewise veto voting preference rule is strategy-proof and non-imposed.

Because coordinatewiseness is equivalent to the independence of irrelevant alternatives, which implies indifference monotonicity we have the following result.

LEMMA 3.5 Every coordinatewise veto voting preference rule is indifference monotonic. 
The following two lemmas establish that a strategy-proof and non-imposed preference rule is a coordinatewise veto voting preference rule. First it is proved that such rules are independent of irrelevant alternatives.

LEMMA 3.6 Let F : $\mathbf{C}^{\mathrm{N}} \rightarrow \mathbf{C}$ be a strategy-proof and non-imposed preference rule. Then $F$ is independent of irrelevant alternatives.

Proof Let $1 \leq \mathrm{i}<\mathrm{j} \leq \mathrm{M}$. Let $\mathrm{p} \in \mathbf{C}^{\mathrm{N}}$ and $\mathrm{S}, \mathrm{T}, \mathrm{V}$ a partition of $\mathrm{N}$ such that $\mathrm{S}=\left\{\mathrm{t} \in \mathrm{N} \mid<\mathrm{a}_{\mathrm{i}}, \mathrm{a}_{\mathrm{j}}>\notin \mathrm{p}(\mathrm{t})\right\}, \mathrm{T}=\left\{\mathrm{t} \in \mathrm{N} \mid<\mathrm{a}_{\mathrm{j}}, \mathrm{a}_{\mathrm{i}}>\notin \mathrm{p}(\mathrm{t})\right\}$ and $\mathrm{V}=\mathrm{N}-(\mathrm{S} \cup \mathrm{T})$. It is sufficient to prove that $v(F(p))_{i j}=v\left(F\left(-E_{i j}^{S}, V^{v}, E_{i j}^{\top}\right)\right)_{i j}$.

We distinguish three cases.

Case $1 \quad v(F(p))_{i j}=-1$. Let $R_{1}=F(p)$ and $\left.R_{2}=R_{1} \cup\left\{<a_{i}, a_{j}\right\rangle\right\}$. Then by monotonicity it follows that $F\left(R_{1}^{S}, R_{2}^{N-S}\right)=R$. Because $C$ is a lattice there are relations $R_{3}, R_{4}, R_{5}, R_{6}, \ldots, R_{k}$ in $C$ such that $R_{k-1}=-E_{i j}, R_{k}=I$ and $R_{1}, R_{2}, R_{3}, R_{4}$ is an elementary square, $R_{3}, R_{4}, R_{5}, R_{6}$ is an elementary square $\ldots$ and $R_{k-3}, R_{k-2}, R_{k-1}, R_{k}$ is an elementary square.

So, by applying lemma 2.6 several times it follows that $F\left(-E_{i j}^{S}, l^{N-S}\right)=-E_{i j}$. Hence, by lemma 2.5 $F\left(-E_{i j}^{S}, I^{V}, E_{i j}^{\top}\right)=-E_{i j}$. So, $v(F(p))_{i j}=v\left(F\left(-E_{i j}^{S}, I^{v}, E_{i j}^{\top}\right)\right)_{i j}$.

Case $2 \quad v(F(p))_{i j}=1$. Is similar to case 1.

Case $3 \quad v(F(p))_{i j}=0$. Let $R_{1}=F(p)-\left\{<a_{i}, a_{j}>\right\}$ and $R_{2}=F(p)$.

By monotonicity it follows that $F(p)=F\left(R_{1}^{S}, R_{2}^{N-S}\right)$.

Similarly to case 1 it follows that $F\left(-E_{i j}^{S}, 1^{N-S}\right)=I$.

By a similar reasoning we also have $F\left(I^{N-T}, E_{i j}^{\top}\right)=I$.

By strategy-proofness, lemma 2.5 and $F\left(-E_{i j}^{S}, N^{S}\right)=1$ it follows that $F\left(-E_{i j,}^{S}, I^{\vee}, E_{i j}^{\top}\right) \in\left\{I, E_{i j}\right\}$. By strategy-proofness, lemma 2.5 and $F\left(I^{N-}, E_{i j}^{\top}\right)=I$ it follows that $F\left(-E_{i j}^{S}, I^{V}, E_{i j}^{\top}\right) \in\{l,-E$ F $\}$. So, $F\left(-S_{i}^{S} E^{V}, I, T E\right)=I$. From which we can conclude that $v(F(p))_{i j}=v\left(F\left(-E_{i j}^{S}, V^{v}, E_{i j}^{\top}\right)\right)_{i j}$.

LEMMA 3.7 Let $\mathrm{F}: \mathbf{C}^{\mathrm{N}} \rightarrow \mathbf{C}$ be a strategy-proof and non-imposed preference rule. Then there is an assignment of disagreements $\lambda$ such that $F=F_{\lambda}$. 
PROOF First we define the assignment of disagreements $\lambda$ for $X \subset N$ and $1 \leq \mathrm{i}<\mathrm{j} \leq \mathrm{M}$ as follows.

$$
\begin{array}{lll}
\lambda(X)_{i j}=-1 & \text { if } & F\left(-E_{i j}^{X}, E_{i j}^{N-X}\right)=-E_{i j}, \\
\lambda(X)_{i j}=0 & \text { if } & F\left(-E_{i j}^{X}, E_{i j}^{N-X}\right)=I \text { and } \\
\lambda(X)_{i j}=1 & \text { if } & F\left(-E_{i j}^{X} E_{i j}^{N-X}\right)=E_{i j} .
\end{array}
$$

By lemma $2.5 F\left(-E_{i j}^{X}, E_{i j}^{N-X}\right) \in\left\{-E_{i j}, I, E_{i j}\right\}$ therefore $\lambda$ is well-defined. Furthermore, by unanimity $\lambda(N)_{i j}=-1$ and $\lambda(\varnothing)_{i j}=1$.

Let $p \in \mathbf{C}^{N}$ and $1 \leq \mathrm{i}<\mathrm{j} \leq \mathrm{m}$.

Let $S, V$ and $T$ be defined according to $p$ as in the previous lemma.

It is sufficient to prove that $F\left(-E_{i j}^{S}, I^{v}, E_{i j}^{\top}\right)=F_{\lambda}\left(-E_{i j}^{S}, I^{v}, E_{i j}^{\top}\right)$.

We distinguish four cases.

Case $1 \lambda(S)_{i j}=-1$. Then by definition we have both $F\left(-E_{i}^{S}, V^{V}, E_{j}^{\top}\right)=-F$ and $F\left(-E_{i j}^{S}, E^{N-S}\right)=-E_{i j}$. So in that case we are done by monotonicity.

Case $2 \quad \lambda(S)_{i j}=0$. Is similar to case 1.

Case $3 \lambda(S \cup V)_{i j} \leq 0$ and $\lambda(S)_{i j}=1$. By definition we have both $F_{\lambda}\left(-E_{i j,}^{S}, I^{V}, E_{i j}^{\top}\right)=1$ and $F\left(-E_{i j}^{S \cup v}, E_{i j}^{\top}\right) \in\left\{-E_{i j}, 1\right\}$.

If $F\left(-E_{i j}^{S \vee V}, E_{i j}^{\top}\right)=I$, then by monotonicity $F\left(-E_{i j}^{S}, I^{\vee}, E_{i j}^{\top}\right)=I$ and we are done.

Suppose $F\left(-E_{i j}^{S \cup V}, E_{i j}^{T}\right)=-E_{i j}$. By definition $F\left(-E_{i j}^{S}, E_{i j}^{N-S}\right)=E_{i j}$.

By lemma 2.5 $F\left(-E_{i j}^{S}, I^{V}, E_{i j}^{\top}\right) \in\left\{-E_{i j}, I, E_{i j}\right\}$.

If $F\left(-E_{i j}^{S}, V^{V}, E_{i j}^{\top}\right)=-E_{i j}$, then by strategy-proofness and lemma $2.5 F\left(-E_{i j}^{S}, E_{i j}^{N-S}\right)=-E_{i j}$. This cannot be the case.

If $F\left(-E_{i j,}^{S},{ }^{V}, E_{i j}^{\top}\right)=E_{i j}$, then by strategy-proofness and lemma $2.5 F\left(-E_{i j}^{S\llcorner V}, E_{i j}^{\top}\right)=E_{i j}$.

This cannot be the case also.

So, $F\left(-E_{i j}^{S}, V^{V}, E_{i j}^{\top}\right)=I$.

Case $4 \lambda(S \cup V)_{i j}=1$. Then by definition we have both $F_{\lambda}\left(一_{F^{S}}^{S}, I^{V}, E_{i j}^{\top}\right)=E$ and $F\left(-E_{i j}^{S \mathrm{SV}}, E_{i j}^{\top}\right)=E_{i j}$. Hence by monotonicity $F\left(-E_{i j}^{S}, I^{V}, E_{i j}^{\top}\right)=E_{i j}$.

Combining lemmas 3.7 and 3.4 we have

CORROLARY 3.8 Let F : $\mathbf{C}^{\mathrm{N}} \rightarrow \mathbf{C}$ be a preference rule then (i) and (ii) are equivalent, where:

(i) $\mathrm{F}$ is strategy-proof and non-imposed, 
(ii) There is an assignment of disagreements $\lambda$, such that $F=F_{\lambda}$.

In Barberà, Gul and Stacchetti [1993] and Barberà, Massó and Neme [1992] similar results are obtained for a larger class of networks. Instead of strict strategyproofness involving preferences which are completely determined by their peak as is done here, there strategy-proofness involving a variety of strict preferences connected with the same peak is studied. Therefore the basic assumptions of both models are different. Moreover, for this reason we cannot use their results here, although the final outcomes of both approaches do not differ very much. 


\section{§ 4. ACYCLIC PREFERENCE RuLES}

In this section non-imposed, indifference monotonic and strategy-proof acyclic preference rules are characterized by acyclic coordinatewise veto voting preference rules, which are based on so called cycle-free assignments of disagreements.

An acyclic preference rule $F: \mathbf{A}^{\mathrm{N}} \rightarrow \mathbf{A}$ is acyclic coordinatewise veto voting preference rule if their is an assignment of disagreements $\lambda$ such that for all $p \in A^{N}$ and all $1 \leq \mathrm{i}<\mathrm{j} \leq \mathrm{M}$

$$
v(F(p))_{i j}=\min _{X \subset N} \max \left\{v(p(t))_{i j} \mid t \in X\right\} \cup\left\{\lambda(X)_{i j}\right\} .
$$

In that case $F$ is denoted by $F_{\lambda}$.

Clearly, contrary to the preference rule case, there exist assignments of disagreements such that the coordinatewise minmax outcome at (5) does not yield an acyclic relation. A necessary and sufficient condition to avoid this is cycle-freeness. An assignment of disagreements $\lambda$ is said to be cycle-free if for every sequence of alternatives $a_{i_{1}}, a_{2}, \ldots a_{k}, a_{k+1}$ and for every sequence of coalitions $S, S, 2 ., S, k$ such that $a_{F_{k+1}} a$; $\#\left\{a_{i}, \ldots, a_{k+1}\right\}=k$, and for all $t \in\{1,2, \ldots, k\} i_{t+1}<i_{t}$ implies $\lambda\left(S_{t}\right) i_{t+1} i_{t}=-1$ and $i_{t}<i_{t+1}$ implies $\lambda\left(\mathrm{N}-\mathrm{S}_{\mathrm{t}}\right)_{\mathrm{i} \mathrm{i}^{\mathrm{t}+1}}=1$ we have that $\cap\left\{\mathrm{S}_{\mathrm{t}} \mid \mathrm{t} \in\{1,2, \ldots, \mathrm{k}\}\right\} \neq \varnothing$.

Let $i_{t}<\dot{t}_{1}$. If $\lambda_{t}(S)_{t_{t+1}}=-1$, then $S$ is decisive over thei pair $<a, a>$ and if $\lambda\left(\mathrm{N}-\mathrm{S}_{\mathrm{t}}\right)_{i_{\mathrm{t} t+1}}=1$, then $\mathrm{S}_{\mathrm{t}}$ is decisive over the pair $<\mathrm{a}_{\mathrm{t}_{t}} \mathrm{a}_{\mathrm{t}_{t+1}}>$ at $\mathrm{F}_{\lambda}$ for some assignment of disagreements. Now suppose that $\lambda\left(\mathrm{N}-\mathrm{S}_{1}\right)_{12}=1, \lambda\left(\mathrm{N}-\mathrm{S}_{2}\right)_{23}=1$ and $\lambda\left(\mathrm{S}_{3}\right)_{13}=-1$ and $S_{1} \cap S_{2} \cap S_{3}=\varnothing$. We will show that $F(p)$ is not acyclic for some profile $p \in A^{N}$. This profile is for all $\mathrm{t} \in \mathrm{N}$ defined as follows

$$
\begin{array}{ll}
p(t)=E_{12} & \text { for } t \in S_{1}-\left(S_{2} \cup S_{3}\right), \\
p(t)=E_{23} & \text { for } t \in S_{2}-\left(S_{1} \cup S_{3}\right), \\
p(t)=-E_{13} & \text { for } t \in S_{3}-\left(S_{1} \cup S_{2}\right), \\
p(t)=E_{12} \cap E_{23} & \text { for } t \in\left(S_{1} \cap S_{2}\right)-S_{3}, \\
p(t)=E_{12} \cap-E_{13} & \text { for } t \in\left(S_{1} \cap S_{3}\right)-S_{2} \text { and } \\
p(t)=E_{23} \cap-E_{13} & \text { for } t \in\left(S_{2} \cap S_{3}\right)-S_{1} .
\end{array}
$$

Now by definition $<a_{1}, a_{2}>,<a_{2}, a_{3}>$ and $<a_{3}, a_{1}>$ are in $\alpha F_{\lambda}(p)$. Hence $F_{\lambda}$ is not an acyclic preference rule in that case. The following lemma shows that cycle-freeness is a necessary and sufficient condition in order that $F_{\lambda}$ is an acyclic preference rule. The definition of this cycle-freeness property is inspired by Trouchon [1993], lemma 7 and theorem 8 . These theorems characterize binary games in constitutional form in a similar 
way.

LEMMA 4.1 Let $\lambda$ be an assignment of disagreements. Consider $F_{\lambda}: \mathbf{C}^{N} \rightarrow \mathbf{C}$. Then (i) and (ii) are equivalent, where:

(i) $\lambda$ is cycle free, and

(ii) for all $p \in \mathbf{A}^{N} \quad F_{\lambda}(p) \in \mathbf{A}$.

PROOF $\quad \neg($ ii $) \Rightarrow \neg($ i $)$ Suppose $F_{\lambda}(p) \notin \mathbf{A}$. Then without loss of generality we have for some $k \leq m \quad<a_{1}, a_{2}>,<a, a_{2}>_{3} . .,<a \quad a_{k} a_{1}>, k a, a_{k}>_{1} \in \quad \mathcal{F}(p)$ Let $\mathrm{T}_{\mathrm{i}}=\left\{\mathrm{t} \in \mathrm{N} \mid<\mathrm{a}, \mathrm{a}_{+1}>\in \alpha \mathrm{p}(\mathrm{t})\right\}$ for $1 \leq \mathrm{i} \leq \mathrm{k}-1$ and $\mathrm{S}=\left\{\mathrm{t} \in \mathrm{N} \mid \gtrless_{\mathrm{a}}{ }_{1} \mathrm{a}>\in \alpha \mathrm{p}(\mathrm{t})\right\}$. Let $S_{i}=N-T_{i}$ for $1 \leq i \leq k-1$. By definition of $F$ and $k_{k} a_{b} a>\epsilon \alpha F(p)$ it follows that $\lambda\left(S_{k}\right)_{1 k}=-1$. By definition of $F_{\lambda}$ and $<a_{i}, a_{i+1}>\in \alpha F(p)$ it follows for all $i \in\{1,2, \ldots, k-1\}$ $\lambda\left(\mathrm{T}_{\mathrm{i}}\right)_{\mathrm{ii}+1}=\lambda\left(\mathrm{N}-\mathrm{S}_{\mathrm{i}}\right)_{\mathrm{ii}+1}=1$. So, $\lambda$ is not cycle free.

$\neg(\mathrm{i}) \Rightarrow \neg$ (ii) Let $\lambda$ have a cycle. Without loss of generalization then there is a number $\mathrm{k} \leq \mathrm{m}$ and coalitions $\mathrm{S}_{1}, \mathrm{~S}_{2}, \ldots, \mathrm{S}_{\mathrm{k}}$ such that for all $1 \leq \mathrm{i} \leq \mathrm{k}-1 \quad \lambda\left(\mathrm{N}-\mathrm{S}_{\mathrm{i}}\right)_{1}=1$ and $\lambda\left(S_{k}\right)_{1 k}=1$ and $S \cap S \cap \cap \ldots \cap S=\varnothing$. Now for all $t \in N$ define $p(t)$ as follows: for all $a_{i}, a_{j} \in A \quad<a_{i}, a_{j}>\in p(t)$ unless

either $\mathrm{i}=1, \mathrm{j}=\mathrm{k}$ and $\mathrm{t} \in \mathrm{S}_{\mathrm{k}}$, or $\mathrm{i}=\mathrm{j}+1 \leq \mathrm{k}$ and $\mathrm{t} \in \mathrm{S}_{\mathrm{j}}$.

Since $S_{1} \cap S_{2} \cap \ldots \cap S_{k}=\varnothing$ it follows that $p \in A^{N}$.

By definition of $F_{\lambda}$ it follows that $<a_{1}, a_{2}>, \ldots,<a_{k-1}, a_{k}>,<a_{k}, a_{1}>\in \alpha F_{\lambda}(p)$.

So, $F_{\lambda}(p) \notin A$.

Next it is shown that non-imposed, indifference monotonic and strategy-proof acyclic preference rules are independent of irrelevant alternatives.

LEMMA 4.2 Let $\mathrm{F}: \mathbf{A}^{\mathrm{N}} \rightarrow \mathbf{A}$ be a non-imposed and strategy-proof acyclic preference rule. Then $F$ is indifference monotonic if, and only if, $F$ is independent of irrelevant alternatives.

ProOF The if-part is evident.

In order to prove the only if-part suppose $F$ is indifference monotonic. Let $1 \leq \mathrm{i}<\mathrm{j} \leq \mathrm{M}$. 
Let $p \in \mathbf{A}^{N}$ and $S, T$ and $V$ be a partition of $N$ such that $S=\left\{t \in N \mid<a_{i}, a_{j}>\notin p(t)\right\}$, $T=\left\{t \in N \mid<a_{j}, a>\notin p(t)\right\}$ and $V=N-(S \cup T)$. It is sufficient to prove that $v(F(p))_{i j}=v\left(F\left(-E_{i j}^{S}, I^{v}, E_{i j}^{\top}\right)_{i j}\right.$. We distinguish three cases.

Case $1 \quad v(F(p))_{i j}=-1$. Let $R_{1}=F(p)$ and $R_{2}=R \cup\{<a, a>\}$. $R \in A$ because $<a_{2}, a_{1}>\in \alpha R_{1}$ and $R_{1} \in A$. Furthermore, there are complete relations $R_{3}, R_{4}, \ldots, R_{k-1}, R_{k}$ in $\mathbf{C}$ such that $R_{k-1}=-E_{i j}, R_{k}=I$, and $R_{1}, R_{2}, R_{3}, R_{4}$ is an elementary square, $R_{3}, R_{4}, R_{5}, R_{6}$ is an elementary square, $\ldots$ and $R_{k-3}, R_{k-2}, R_{k-1}, R_{k}$ is an elementary square. It is without loss of generality to suppose that $R_{1} \subset R_{3} c_{5} R \subset{ }_{\cdot k \cdot 1} \subset R$ ij $=-E$ and $R_{2} \subset R_{4} \subset \ldots \subset R_{k}=I$. Therefore $R_{3}$ is obtained from $R_{1}$ by changing a strict preference over a single pair into an indifference. Hence, $R_{3}$ is in $\mathbf{A}$. Similarly it follows that $R_{4}, R_{5}, \ldots, R_{k} \in A$. So, all the squares are in $\mathbf{A}$. But then similarly as in case 1 of lemma 3.6 it follows that $v(F(p))_{i j}=v\left(F\left(-E_{i j}^{S}, I^{v}, E_{i j}^{T}\right)\right)_{i j}$.

Case $2 \quad v(F(p))_{i j}=1$. Is similar to case 1.

Case $3 \vee v(F(p))_{i j}=0$. Then by indifference monotonicity it follows that $v(F(p))_{i j}=v\left(F\left(-E_{i j}^{S}, I^{v}, E_{i j}^{T}\right)\right)_{i j}$

Now similarly to 3.7 the following result can be obtained.

LEMMA 4.3 Let $\mathrm{F}: \mathbf{A}^{\mathrm{N}} \rightarrow \mathbf{A}$ be strategy-proof, non-imposed and indifference monotonic. Then there is an assignment of disagreements $\lambda$ such that $F=F_{\lambda}$.

Combining lemma 4.1 up to 4.3 yields the following characterization of strategy-proof, non-imposed and indifference monotonic acyclic preference rules. 
CORROLARY 4.4 Let $\mathrm{F}: \mathbf{A}^{\mathrm{N}} \rightarrow \mathbf{A}$ be an acyclic preference rule.

Then (i) and (ii) are equivalent, where:

(i) $\mathrm{F}$ is strategy-proof, non-imposed and indifference monotonic

(ii) There is a cycle-free assignment of disagreements $\lambda$, such that $F=F_{\lambda}$. 


\section{REFERENCES}

- $\quad$ Andjiga N.G. and J. Moulen, [1988]: "Binary Games in Constitutional Form and Collective Choice", Mathematical Social Sciences, 16, 189-201.

- $\quad$ Arrow K.J., [1963]: Social Choice and Individual Values, Wiley, New York.

- Baigent N., [1987]: "Preference Proximity and Anonymous Social Choice", Quarterly Journal of Economics, 102, 161-169.

- Bandyopadhyay T., [1983]: "Coalitional Manipulation and the Pareto Rule", Journal of Economic Theory, 29, 359-363.

- $\quad$ Barberà S., [1977]: "Manipulation of Social Decision Functions", Journal of Economic Theory, 15, 266-278.

- Barberà S. and B. Peleg, [1990]: "Strategy-proof voting schemes with Continous Preferences", Social Choice and Welfare, 7, 31-38.

- $\quad$ Barberà S., F. Gul and E. Stacchetti, [1993]: "Generalized Median Voter Schemes and Committees", Journal of Economic Theory, 61, 262-289.

- $\quad$ Barberà S., J. Massó and A. Neme, [1992]: "Voting under Constraints", working paper, Barcelona, Spain.

- $\quad$ Barberà S., H. Sonnenschein and L. Zhou, [1991]: "Voting by Committees", Econometrica, 59, 595-609.

- $\quad$ Barthélemy J.P. and M. Monjardin, [1981]: The Median Procedure in Cluster Analysis and Social Choice Theory", Mathematical Social Sciences, 1, 235-267. 
- $\quad$ Black D., [1948]: "On the Rationale of Group Decision Making", Journal of Political Economy, 56, 23-34.

- Blair D.H. and R.A. Pollack, [1982]: "Acyclic Collective Choice Rules", Econometrica, 50, 931-943.

- Blau J.H. and R. Deb, [1977]: "Social Decision Function and the Veto", Econometrica, 45, 871-879.

- Bloomfield S.D., [1976]: "A Social Choice Interpretation of the von NeumannMorgenstern Game", Econometrica, 44, 105-114.

- $\quad$ Bogart K.P., [1973]: "Preference Structures I: Distances Between Transitive Preference Relations", Journal of Mathematical Sociology, 3, 49-67.

- $\quad$ Border K.C. and J.S. Jordan, [1983]: "Straightforward Elections, Unanimity and Phantom Voters", Review of Economic Studies, 50, 153-170.

- Bossert W. and T. Storcken, [1992]: "Strategy-proofness of Social Welfare Functions: The Use of the Kemeny Distance Between Preference Orderings", Social Choice and Welfare, 9, 345-360.

- Brown J.D., [1975]: "Aggregation of Preferences", Quarterly Journal of Economics, 3, 456-469.

- $\quad$ Campbell D.E. and S.I. Nitzan, [1986]: "Social Compromise and Social Metric", Social Choice and Welfare, 3, 1-16.

- Dutta B., [1982]: "Multivalued Social Choice Functions and Strategic Manipulation with Counterthreats", Mathematical Social Sciences, 2, 113-122.

- $\quad$ Farkas D. and S.I. Nitzan, [1979]: "The Borda Rule and Pareto Stability: a Comment", Econometrica,47, 1305-1306. 
- $\quad$ Feldman A., [1979]: "Manipulation of Social Welfare Functions", Journal of Economic Theory, 13, 217-228.

- Gärdenfors P., [1976]: "Manipulation of Social Choice Functions", Journal of Economic Theory, 13, 217-228.

- Gibbard A., [1973]: "Manipulation of Voting Schemes: a General Result", Econometrica, 41, 587-601.

- $\quad$ Kelly J.S., [1977]: "Strategy-proofness and Social Choice Functions without Single Valuedness", Econometrica, 45, 439-446.

- $\quad$ Kelsey D., [1985]: "Acyclic Choice and Group Veto", Social Choice and Welfare, 2, 131-137.

- Kemeny J.G. and J.L. Snell, [1962]: Mathematical Models in Social Sciences, Ginn and Compnay, New York.

- Kendall M.G., [1970]: Rank Correlation Methods, Giffin, London.

- $\quad$ Kim K.H. and F.W. Roush, [1984]: "Nonmanipulability in Two Dimensions", Mathematical Social Sciences, 8, 29-43.

- $\quad$ Le Breton M., [1987]:"On the Core of Voting Games", Social Choice and Welfare, 4, 295-305.

- $\quad$ Lerer E. and S.I. Nitzan, [1985]: "Some General Results on the Metric Rationalization for Social Decision Rules", Journal of Economic Theory, 37, 191-201.

- $\quad$ Mas-Colell A. and H. Sonnenschein, [1972]: "General Possibility Theorems for Group Decision Functions", Review of Economic Studies, 39, 185-192.

- $\quad$ Mirkin B.G., [1979]: Group Choice, Winston, Washington. 
- Moulin H., [1980]: "On Strategy-proofness and Single Peakedness", Public Choice, 35, 437-455.

- Moulin H., [1985]: "From Social Welfare Ordering to Acyclic Aggregation of Preferences", Mathematical Social Sciences, 9, 1-17.

- Nakamura K., [1979]: "The vetoers in a Simple Game with Ordinal Preferences", International Journal of Game Theory, 8, 55-61.

- $\quad$ Pattanaik P.K., [1978]: Strategy and Group Choice, North-Holland, Amsterdam.

- Peleg B., [1978]: "Representations of Simple Games by Social Choice Functions", International Journal of Game Theory, 7, 81-94.

- $\quad$ Peleg B., [1984]: Game Theoretic Analysis of Voting in Committees, Cambridge University Press.

- $\quad$ Peters H., H. v.d. Stel and T. Storcken [1991]: "On Uncompromisingness and Stategy-Proofness", Report M91-15, Maastricht, The Netherlands.

- $\quad$ Peters H., H. v.d. Stel and T. Storcken [1992]: "Pareto Optimality, Anonimity, and Strategy-Proofness in Location Problems", International Journal of Game Theory, 21, 221-235.

- Ramamurthy K.G., [1990]: Coherent Structures and Simple Games, Kluwer Academic Publishers, Dordrecht.

- Satterthwaite M.A., [1975]: "Strategy-Proofness and Arrow's Conditions: Existence and Correspondence Theorem for Voting Procedures and Social Welfare Functions", Journal of Economic Theory, 10, 187-217.

- $\quad$ Sen A.K., [1986]: "Social Choice Theory", In: K.J. Arrow and M.D. Intriligator (eds) Handbook of Mathematical Economics, vol III, North-Holland, Amsterdam, 1073-1181. 
- $\quad$ Stehling F., [1978]: "Indices of Preference Inequality and the Construction of Social Preference Relations", In: W. Eichhorn, O. Opitz and R.W. Shepard (eds) Theory and Applications of Economic Indices, Physica Verlag, Würzburg.

- Trouchon M., [1993]: "Voting Games and Acyclic Collective Choice Rules", Report, Cahier 9315, GREPE, University of Laval. 